\title{
PENGARUH LATIHAN PLYOMETRIC DI PASIR TERHADAP POWER OTOT TUNGKAI SISWI DI SMKN1 KOTA BENGKULU TAHUN 2017/2018
}

\author{
Melfi Cahyadi
}

Penjas FKIP UNIB, e-mail: Melficahyadiii@gmail.com

\author{
Dian Pujianto \\ Universitas Bengkulu \\ Arwin \\ Universitas Bengkulu
}

\begin{abstract}
Abstrak
Penelitian ini bertujuan untuk mengkaji pengaruh latihan plyometric di pasir terhadap peningkatan power otot tungkai pada siswi di SMKN1 Kota Bengkulu tahun 2017/2018. Metode yang digunakan dalam penelitian ini adalah metode eksperimen. Dengan sampel siswi yang berjumlah 32 orang. Instrumen penelitian ini untuk mengetahui peningkatan power otot tungkai dengan menggunakan tes vertical jump. Teknik analisis data menggunakan uji-t. Hasil penelitian di peroleh $\mathrm{t}$ hitung $=10,654$ jika di bandingkan dengan nilai $t$ tabel $=1,696$ maka nilai $t$ hitung $>t$ tabel. Ini berarti ada pengaruh yang signifikan dari latihan plyometric di pasir terhadap power otot tungkai siswi di SMKN1 Kota Bengkulu.
\end{abstract}

Kata kunci : plyometric pasir, power otot tungkai.

\begin{abstract}
The Effect Of Plyometric Exercise on the Sand toward Female Students Leg Muscle Power at SMKN1 Kota Bengkulu in Academic Year 2017/2018. Thesis. Bengkulu : Bachelor Degree Program of Pyhsical Education, University of Bengkulu, 2018. This study aimed at examining the effect of plyometric exercise on sand toward the increasing of leg muscle power in female students at SMKN1 Kota Bengkulu in academic year 2017/2018. The method used in this research was experiment metho. with 32 students as the sample of research. The instrument used to know the increasing of leg muscle power in this research was by using vertical jump test. Data analysis techniques used was t-test. The results of this research showed that t-count $=10,654$ when compared to $t$-table $=1.696$ so the value of $t$-count $>t$ table. This meant that there was a significant effect of plyometric exercise on sand toward female students' leg muscle power at SMKN1 Kota Bengkulu.
\end{abstract}

Key words: plyometric sand, leg muscle power. 


\section{PENDAHULUAN}

Pendidikan adalah pembelajaran dimana disana ada pengetahuan, keterampilan, dan kebiasaan yang diturunkan dari satu generasi ke generasi selanjutnya melalui pengajaran, pelatihan, dan penelitian. Dalam pendidikan ada banyak aspek yang terdapat di dalamnya, antara lain :1. Aspek kognitif, 2. Aspek afektif, dan 3. Aspek psikomotorik. Aspek psikomotorik merupakan ranah yang berkaitan dengan keterampilan (skill) biasanya berhubungan dengan aktifitas fisik seperti lari, melompat, melempar, menendang. Olahraga adalah aktifitas untuk melatih tubuh seseorang, tidak hanya secara jasmani tetapi juga secara rohani. Salah satu faktor yang berperan dalam pencapaian prestasi olahraga adalah faktor fisik terutama power otot tungkai. Power otot tungkai adalah salah satu bagian terpenting dari kegiatan olahraga, karena dengan tungkai yang kuat seseorang bisa berlari, melompat, dan melakukan semua aktifitas dengan baik. Di SMKN1 Kota Bengkulu ditemukan ketika dalam pelajaran penjas ketika siswi mengambil nilai vertical jump hasil lompatanya masih belum maksimal, semua itu terlihat dari hasil raihan yang siswi dapatkan. Bentuk latihan yang dapat diberikan adalah dengan memberikan berbagai macam variasi latihan loncat, karena dengan variasi latihan akan membuat sampel merasa senang dan tidak menimbulkan rasa jenuh ketika latihan. Salah satu latihan yang dapat diberikan untuk meningkatkan power otot tungkai adalah dengan latihan plyometric di pasir. Latihan plyometric di pasir adalah suatu bentuk pengembangan loncat, biasanya ketika latihan loncat sampel loncat di tempat yang datar, kali ini dengan latihan plyometric di pasir maka sampel akan latihan loncat di tempat yang tidak datar, karena kita tahu ketika berjalan di pasir kaki kita akan terasa sedikit berat karena kaki kita akan masuk kedalam pasir oleh sebab itu peneliti memberikan latihan plyometric di pasir dengan tujuan memberikan beban alami kepada siswi di SMKN1 Kota Bengkulu, sehingga power otot tungkai siswi di SMKN1 Kota Bengkulu menjadi lebih baik lagi.

Latihan adalah aktifitas untuk meningkatkan kualitas fungsi sistem organ tubuh manusia sehingga mempermudah atlet dalam penyempurnaan geraknya (Apta dan Febi, 2015:47). Dan latihan adalah proses dimana seseorang atlet dipersiapkan untuk peforma tertinggi (Bompa dan Gregory, 2009:2). Secara umum tujuan latihan adalah membantu para pembina, pelatih, guru olahraga agar dapat menerapkan dan memiliki kemampuan konseptual serta keterampilan dalam membantu mengungkapkan potensi atlet mencapai puncak prestasi (Apta dan Febi, 2015:49).

Terminologi plyometrics pertama kali dimunculkan pada tahun 1975 
oleh Fred Wilt salah seorang pelatih atletik warga Amerika. Istilah 'plyometric' adalah sebuah kombinasi kata yang berasal dari bahasa latin, yaitu 'plyo' dan 'metrics' yang memiliki arti peningkatan yang dapat diukur (Chu,1992), dalam (Johansyah Lubis, 2013:73). Plyometric adalah kunci pengembangan kekuatan atletik yang relevan dengan mayoritas olahraga (Jhon Sheperd, 2006:94). Plyometric adalah pelatihan teknik yang digunakan oleh atlet semua jenis olahraga untuk meningkatkan kekuatan dan daya ledak (Menurut Sankarmani, dkk. dalam Danang Pujo Broto, 2015:175-176). Dan plyometric adalah metode latihan untuk kekuatan kecepatan (power) dengan menggunakan beban utama badan atlet itu sendiri yang bertujuan untuk menghubungkan kekuatan maksimal yang telah dimiliki oleh atlet kedalam aplikasi gerakan cepat dan kuat sesuai dengan olahraga tertentu (Ria Lumintuarso,2013:61). Adapun cara kerja plyometric dalam latihan : otot yang teulur sebelum berkontraksi secara konsentris, akan berkontraksi dengan tenaga yang kuat dan lebih sering. Contoh : klasifikasinya dalam kegiatan lompat tinggi. Dengan menggunakan hukum gravitasi dengan cepat saat melompat (Lan dejavu blog yang di akses pada 3 Januari 2018, pukul 20.03).

Power adalah kemampuan untuk mengeluarkan kekuatan secara eksplosif atau dengan cepat (Corbin dalam Arsil, 2008:71). Power adalah hasil dari kekuatan dan kecepatan (Harsono, 2015:162). Dan power adalah suatu kemampuan gerak yang sangat penting untuk menunjang aktivitas pada setiap cabang olahraga (Widiastuti, 2011:100). Latihan power dapat meningkatkan fungsi fisik karena melibatkan gerakan dengan kecepatan tinggi (Miszko dalam Apta dan Febi, 2015:13). Kyrolainen, dkk. dalam Apta dan Febi, (2015:137) mengatakan bahwa latihan power dapat meningkatkan jika diberikan di awal latihan sehingga menciptakan kondisi yang lebih baik dengan fungsi refleks yang kuat, dan menurut (Potach dalam Danang Pujo Broto, 2015:176) latihan power dikerjakan dengan cepat, kuat dan rekreatif.

Otot tungkai terdiri dari otot tungkai atas dan otot tungkai bawah. Tungkai atas terdiri atas pangkal paha sampai lutut, sedangkan otot tungkai bawah terdiri atas tulang pangkal paha, tulang paha, tulang kering, tulang betis, tulang tempurung lutut, tulang pangkal kaki, tulang ruas jari kaki (Syaifuddin, 2006:100-103).

Kyrolainen, dkk. dalam Apta dan Febi, (2015:137) mengatakan bahwa latihan power dapat meningkatkan jika diberikan di awal latihan sehingga menciptakan kondisi yang lebih baik dengan fungsi refleks yang kuat, dan menurut (Potach dalam Danang Pujo Broto, 2015:176) latihan power dikerjakan dengan cepat, kuat dan rekreatif. Dan latihan power akan menghasilkan kekuatan dan kecepatan lebih saat kita hendak 
melakukan gerakan yang membutuhkan eksplosif.

\section{METODE}

Metode ini melatih daya ledak (eksplosive power) otot tungkai, yang merupakan gabungan dari dua unsur kekuatan dan kecepatan. Kelebihan dari latihan ini ketika siswi loncat di pasir maka kaki siswi akan masuk kepasir dan ketika siswi ingin menolak (loncat) ke atas akan menjadi beban yang akan menyebabkan ketika siswi loncat di tempat yang datar maka tinggi loncatan siswi tersebut akan bertambah. Penelitian ini berjenis penelitian eksperimen. Penelitian ini dibagi menjadi 3 tahapan yakni pretest, pemberian perlakuan (treatment), dan post test. Desain yang di gunakan dalam penelitian ini adalah one group pretest-posttest design. Dalam design ini tidak menggunakan kelompok kontrol dan subyek tidak ditempatkan secara acak. Kelebihan dari design ini adalah dilakukanya pretest dan posttest sehingga dapat diketahui pasti perbedaan hasil akibat perlakuan yang diberikan (treatment).

Populasi dalam penelitian ini adalah seluruh siswi aktif di SMKN1 Kota Bengkulu, teknik pengambilan sampel dalam penelitian ini menggunakan teknik purposive sampling. Artinya teknik pengambilan sampel dilakukan secara sengaja sesuai dengan persyaratan sampel yang di tentukan. Berdasarkan teknik sampel di atas maka sampel dalam penelitian ini berjumlah 32 orang.

Dalam penelitian ini terdapat dua variabel yaitu variabel bebas dan variabel terikat. Variabel bebas dalam penelitian ini adalah latihan plyometric di pasir. Adapun yang menjadi variabel terikat dalam penelitian ini adalah power otot tungkai siswi di SMKN1 Kota Bengkulu. Tekhnik pengumpulan data menggunakan tes vertical jump dengan validitas 0,966 dan reliabilitas 0,923 (Danang Pujo Broto).

\section{HASIL DAN PEMBAHASAN}

Untuk mendapatkan hasil dalam penelitian ini maka peneliti terlebih dahulu mengola data pretest dan posstest menggunakan tekhnik analisis data, adapun yang terdapat di dalam tekhnik analisis data adalah uji prasyarat dan uji hipotesis. Di dalam uji prasyarat ada 2 perhitungan yang di lakukan peneliti. Yang pertama menghitung normalitas data pretest dan posstest. Yang kedua menghitung homogenitas data pretest dan data posstest menggunakan uji f. Setelah selesai dengan uji prasyarat, barulah peneliti mengerjakan uji hipotesis dengan menggunakan uji t pengaruh. Uji $t$ pengaruh bertujuan untuk menjawab hipotesis yang di ajukan peneliti yaitu ada tidaknya pengaruh latihan plyometric di pasir terhadap power otot tungkai siswi di SMKN1 Kota Bengkulu. 
1) Uji Prasarat.

a. Penghitungan Normalitas

Penghitungan normalitas dengan menggunakan rumus Liliefors. Hasil yang diperoleh adalah :

Tabel 5 Uji Normalitas

\begin{tabular}{|c|c|c|c|c|c|c|}
\hline \multirow[t]{2}{*}{$\begin{array}{l}\mathbf{N} \\
\mathbf{0}\end{array}$} & \multirow[t]{2}{*}{$\mathbf{n}$} & \multicolumn{2}{|r|}{$\begin{array}{l}\text { Aw } \\
\text { al }\end{array}$} & Tes & $\begin{array}{l}\text { Ak } \\
\text { hir }\end{array}$ & Ket \\
\hline & & Lo & $\mathbf{L}_{\mathbf{T}}$ & Lo & $\mathbf{L}_{\mathbf{T}}$ & $\begin{array}{l}\text { Distr } \\
\text { ibusi }\end{array}$ \\
\hline \multirow[t]{3}{*}{1} & 3 & 0,1 & 0,1 & 0,1 & 0,1 & Nor \\
\hline & 2 & 09 & 56 & 01 & 56 & mal \\
\hline & & 0 & 6 & 5 & 6 & \\
\hline
\end{tabular}

Dari tabel di atas, diketahui $\mathrm{L}_{0}<$ Ltabel, Berarti data yang di ambil dari satu kelompok eksperimen yang di teliti mempunyai distribusi Normal.

b. Uji Homogenitas

Uji homogenitas menggunakan uji $\mathrm{F}$ dengan derajat kebebasan dan taraf signifikansi $a=0,05$ pada tabel berdistribusi F. Hasil yang diperoleh adalah :

Tabel 6 Uji Homogenitas

\begin{tabular}{c|c|c|c}
$\mathbf{N}$ & $\begin{array}{c}\text { Varia } \\
\mathbf{0}\end{array}$ & $\begin{array}{c}\text { Standar } \\
\text { bel }\end{array}$ & $\begin{array}{c}\text { Varians } \\
\mathbf{( S}^{\mathbf{2}}\end{array}$ \\
\hline 1 & $\begin{array}{c}\text { Tes } \\
\text { Awal }\end{array}$ & 5,899 & 34,80 \\
\hline 2 & $\begin{array}{c}\text { Tes } \\
\text { Akhir }\end{array}$ & 5,896 & 34,77 \\
\multirow{2}{*}{ Fhitung $=$ Varians Terbesar } & Varians Terkecil
\end{tabular}

Fhitung $=\underline{34,80}=1,0008$

34,77

Dari perhitungan diatas di dapat nilai $F_{\text {hitung }}=1,0008$ sedangkan nilai $f_{\text {tabel }}$ pada taraf signifikan $a=0,05$ $=4,15$. F Fitung $<F_{\text {tabel }}$ yaitu $1,0008<4,15$ ini berarti tidak terdapat perbedaan dari masing-masing variabel atau harga variansya Homogen.

\section{Uji Hipotesis}

Penelitian ini bertujuan untuk mengetahui pengaruh latihan plyometric di pasir terhadap power otot tungkai pada siswi di SMKN1 Kota Bengkulu. Analisis data yang digunakan untuk menjawab hipotesis yang diajukan yaitu ada tidaknya pengaruh latihan plyometric di pasir terhadap power otot tungkai pada siswi di SMKN1 Kota Bengkulu.

Setelah dilakukan penghitungan normalitas dan homogenitas, selanjutnya dilakukan pengujian hipotesis menggunakan uji-t sebagai berikut:

Tabel 7 Uji T Berdasarkan hasil tes awal dan tes akhir vertical jump

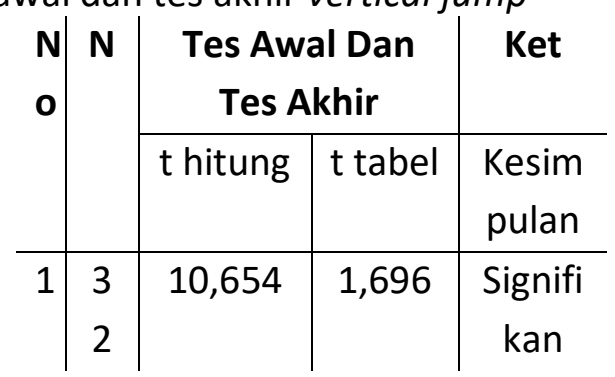

Dari hasil data yang terkumpul maka penghitungan menunjukkan $t$ 
hitung sebesar $10,654>t$ tabel $=1,696$. Berarti signifikan.

Selanjutnya hipotesis yang menyatakan bahwa ada pengaruh latihan plyometric di pasir terhadap power otot tungkai siswi di SMKN1 Kota Bengkulu, diterima.

Latihan yang di laksanakan selama 16 kali pertemuan terbukti berhasil memberikan pengaruh terhadap peningkatan power otot tungkai siswi di SMKN1 Kota Bengkulu. Tidak hanya itu, masih ada banyak faktor lain yang bisa mempengaruhi peningkatan power otot tungkai. Gizi adalah satu hal penting dalam peroses peningkatan power otot tungkai, seperti yang dikatakan Djoko Pekik I, $(2006,22)$ zat gizi sangat di perlukan oleh tubuh karena mempunyai manfaat yang besar terhadap pertumbuhan dan perkembangan manusia. Dan kebutuhan gizi harus dicukupi secara baik karena terjadinya proses pertumbuhan yang cepat dalam aktifitas yang tinggi. (Almatsier,2009:32).

Peningkatan power otot tungkai terlihat pada perbandingan perubahan rata-rata pretest dan posttest. Dari data yang sudah diperoleh, hasil pretest sebesar 28.69 dan hasil rata-rata posttest sebesar 31 dengan selisih 2,31. Mengingat pentingnya kekuatan power pada otot tungkai dalam aktifitas fisik maka perlu sekali upaya untuk meningkatkan kekuatan pada power otot tungkai siswi di SMKN1 Kota
Bengkulu. Power otot tungkai siswi dapat meningkat apabila latihan dilakukan secara terprogram, terencana, dan dilakukan dengan benar. Dengan demikian dapat di simpulkan bahwa penelitian yang telah dilakukan dengan pemberian latihan plyometric di pasir terbukti dapat meningkatkan power otot tungkai siswi di SMKN1 Kota Bengkulu.

\section{Simpulan}

Berdasarkan hasil penelitian di atas dapat di simpulkan latihan plyometric di pasir berpengaruh terhadap peningkatan power otot tungkai siswi di SMKN1 Kota Bengkulu. Peningkatan power otot tungkai terlihat pada perbandingan perubahan rata-rata pretest dan posttest. Dari data yang sudah diperoleh, hasil pretest sebesar 28.69 dan hasil rata-rata posttest sebesar 31 dengan selisih 2,31.

Hasil penelitian menunjukkan bahwa selisih mean antara pretest dan posttest siswi setelah mengikuti program latihan plyometric di pasir sebanyak 16 kali pertemuan dapat menunjukkan peningkatan terhadap power otot tungkai siswi.

Dan dari hasil t hitung sebesar 10,654 lebih > dari t tabel 1,696. Maka data hasil pretest dan posstest di nyatakan signifikan. Dengan demikian hipotesis yang berbunyi "Ada pengaruh latihan plyometric di pasir terhadap power otot tungkai siswi di SMKN1 Kota Bengkulu", diterima. 


\section{Saran}

1. Bagi guru atau pelatih untuk memberikan latihan yang lebih bervariasi lagi sebagai upaya untuk mengurangi kejenuhan latihan.

2. Sebaiknya siswi senantiasa meningkatkan latihan plyometric di pasir, untuk mencapai prestasi yang lebih baik.

3. Bagi peneliti yang ingin melanjutkan penelitian ini agar dapat menjadikan penelitian ini sebagai bahan informasi dan penelitian dengan populasi atau sampel yang berbeda dan dalam jumlah yang lebih banyak lagi.

\section{DAFTAR PUSTAKA}

Annas, Mohamad (2014). Jurnal Profil Tingkat Kesegaran Jasmani Mahasiswa PJKR Jalur Undangan. Semarang. Jurnal olahraga pendidikan, 1(3):17.

Alexon.(2015). Statistik Untuk Penelitian Pendidikan. Bengkulu: FKIP Universitas Bengkulu

Bompa, Tudor O, dan Haff, G Gregory. (2009). Periodazition : Theory and Methotology Of Training. Human Kinetics (Advantage Consignment).

Broto, Danang Pujo (2015). Pengaruh Latihan Pliometrics Terhadap Power Otot Tungkai Atlet Remaja Bola Voli. Jurnal motion VI(2):174-185.
Edwan, Ari, dan Bogy. 2017. "Pengaruh Metode Latihan Plyometric Terhadap Kemampuan Jumping Smash Bola Voli Siswa Ekstrakurikuler SMPN 1 Bermani Ilir Kabupaten Kepahiang" Jurnal Kinestetik, Vol. 1 (1).

Harsono.(2015). Kepelatihan Olahraga. Bandung: PT Remaja Rosdakarya.

Lubis, Johansyah. (2013). Panduan Praktis Penyusunan Program Latihan. Jakarta: PT Raja Grafindo Persada.

Pujianto, Dian dan Bayu Insantyo. (2013). Dasar- Dasar Penelitian Pendidikan Jasmani. Bengkulu: FKIP Universitas Bengkulu.

Sheperd, Jhon. (2006). The Complete Guide To Sport Training. London: A\&C Black Publishers Ltd.

Sudiana, I Ketut. (2009). Pengaruh Latihan Loncat Tegak Di Tanah Berpasir Dan Tidak Berpasir Terhadap Kekuatan, Kecepatan, Dan Power Otot Tungkai. Jurnal Pendidikan Dan Pengajaran. (42)2:145150.

Sugiyono. (2006). Metode Penelitian Kuantitatif Kualitatif dan $R \& D$. Bandung: Alfabeta. 
Syaifuddin.(2006). Anatomi Fisiologi Untuk Mahasiswa Keperawatan. Jakarta:EGC.

Tangkudung, James. (2012). Kepelatihan Olahraga Pembinaan Prestasi Olahraga. Jakarta: Cerdas jaya ,(2016).Macam-macam Metodologi Penelitian. Jakarta: Lensa Media Pustaka Indonesia

Widiastuti.(2011). Tes dan Pengukuran Olahraga. 